Beata Baczyńska (D)

Uniwersytet Wroctawski beata.baczynska@uwr.edu.pl

\title{
Mnemósine Despedida de la profesora Teresa Eminowicz-Jaśkowska
}

En 2008, hace diez años, el séptimo número del anuario Studia Iberystyczne se dedicó a quien lo había puesto en marcha por primera vez, a la profesora Teresa Eminowicz-Jaśkowska. En el número decimoséptimo queremos despedirnos de ella después de que nos dejara el 17 de julio de 2018. En su último recorrido terrenal, el 23 de julio de 2018, en el cementerio Rakowicki de Cracovia, la profesora estuvo acompañada, además de sus personas más cercanas, de antiguos colaboradores y alumnos.

Una de las primeras lecturas que asocio con la profesora Teresa Eminowicz-Jaśkowska es Mnemosyne. Rzecz o powinowactwie literatury i sztuk plastycznych de Mario Praz (Varsovia 1981). Este libro, que se distingue por el color de patina de la sobrecubierta, se publicó en el mismo año en el que comencé mis estudios en la Universidad Jaguelónica. No se encuentra por casualidad en mi biblioteca: durante las primeras clases de Introducción al estudio de la literatura española, la todavía licenciada Teresa Eminowicz nos dio, a sus estudiantes del primer año, las referencias bibliográficas del libro, poniendo el listón muy alto a los principiantes noveles de la Iberística de Cracovia. 
Le estoy muy agradecida por ello a mi profesora. Siempre que vuelvo al Mnemósine de Mario Praz, sus páginas, ineludiblemente amarillentas año tras año, me traen a la memoria un peculiar recuerdo: la dificultad con la que, por primera vez, me abría paso por el denso y erudito texto del polígrafo italiano, que remitía a una rica iconografía que obligaba a usar la imaginación. Cada vez que acudo a este libro vuelve a mi memoria el sentimiento de aquella satisfacción y de aquel enorme placer en el esfuerzo intelectual, como ya apuntaba Baltasar Gracián en su Discurso VII del tratado Agudeza y arte de ingenio (1648): „La verdad, cuanto más dificultosa, es más agradable, y el conocimiento que cuesta, es más estimado".

Precisamente a Baltasar Gracián - Baltasar Gracián: hiszpański pisarz i moralista barokowy (Cracovia 2003) - dedicó su último libro la profesora Eminowicz. En el ejemplar que la profesora me regaló, su dedicatoria, fechada del 28 de mayo de 2003, rezaba en polaco: „Un libro que, aunque pequeño, tal vez sea útil. Como expresión de amistad y de ánimo a los logros de los hispanistas". Con el paso de los años, estas palabras y los deseos que albergan, especialmente después de que la profesora Eminowicz se retirara de la vida académica, han venido cobrando para mí una importancia cada vez mayor.

Soy discípula de la profesora Eminowicz con pleno conocimiento de lo que esto significa. Durante los siguientes años de mis estudios me examiné con ella de Historia de la Literatura española y bajo su dirección (ya como la doctora Teresa Eminowicz) escribí mi tesina de licenciatura. Tras terminar los estudios, gracias a su recomendación, formé parte del equipo de los hispanistas creado por el profesor Piotr Sawicki en el Instituto de Filología Románica de la Universidad de Wrocław.

Tan solo ahora, con la perspectiva de los años pasados desde que obtuve el título académico de la Universidad Jaguelónica en Cracovia (número de libreta Fi/691), y en el contexto de los cambios que a partir de este año esperan a la enseñanza superior en Polonia, estoy en condiciones de valorar en su totalidad lo que fue capaz de lograr la profesora Eminowicz para los estudios de hispánicas de Cracovia y de Polonia, a pesar de las vicisitudes del destino, en unas circunstancias 
muy difíciles entre los años 70 y 80 del siglo pasado. Sobre todo porque fue ella, quien, a principios de los 90, se convirtió en una impulsora infatigable de la integración de los hispanistas polacos.

La profesora Eminowicz estuvo entre los fundadores de la Asociación Polaca de Hispanistas, creada en $1985^{1}$. Por iniciativa suya, apenas una semana después de la reunión que fundara la Asociación en Varsovia, tuvo lugar del 15 al 17 de diciembre de 1985 en la localidad de Mogilany, cercana a Cracovia, el Primer Simposio de Hispanistas Polacos con ocasión del décimo aniversario de los estudios de hispánicas de la Universidad Jaguelónica.

Para mi generación, para nosotros que habíamos comenzado nuestro camino académico profesional en el umbral de la transición democrática en Polonia, se abrían completamente nuevas perspectivas de docencia y de investigación, incomparables con las condiciones en las cuales habían trabajado hasta entonces nuestros profesores y mentores. La profesora Eminowicz formaba parte de ese grupo de personas que se afanaban con ahínco para que pudiéramos beneficiarnos plenamente de estas nuevas posibilidades tanto en el país como en el extranjero.

Con este propósito, en 1999, la profesora Eminowicz creó el anuario científico Studia Iberystyczne, cuyo anticipo había sido un conjunto de estudios en polaco, publicados en 1994, precisamente con ese título, que la profesora Urszula Dąbska-Prokop, una de las redactoras del tomo, introducía de la siguiente manera: "Los artículos están escritos en polaco, de manera que estos trabajos de la Iberística de Cracovia despertarán el interés del lector polaco, aportándole un amplio abanico cultural español, antiguo y contemporáneo, tanto de la Península Ibérica como de América Latina".

La profesora Eminowicz hizo suya la misión de promover internacionalmente el hispanismo polaco. En 1995, con ocasión del vigésimo aniversario de los estudios de hispánicas de la Universidad Jaguelóncia, organizó en Cracovia un gran simposio dedicado a las relaciones

${ }^{1}$ La profesora Teresa Eminowicz-Jaśkowska desempeñó a lo largo de los años diferentes cargos en la Junta Directiva de la Asociación Ploaca de Hispanistas. Véase http://www.pshis.pl/o-nas-sobre-nosotros/, (15.10.2018). 
de la Europa Central y del Este con el ámbito cultural hispanohablante: Europa del Centro y del Este y el Mundo Hispánico. Simposio Internacional de Hispanistas. Cracovia, 26-28 de octubre de 1995. Diez años más tarde repitió la invitación a los hispanistas polacos y extranjeros. También en Cracovia tuvo lugar el congreso internacional Retos del hispanismo en la Europa Central y del Este. Cracovia, 14-15 de octubre de 2005. Estos dos acontecimientos fueron de una importancia fundamental para el desarrollo de los estudios de hispánicas en Polonia y de su imagen en Europa. En el marco del congreso, en 2005, en el Collegium Novum de la Universidad Jaguelónica se debatió sobre los retos del hispanismo contemporáneo en el contexto mundial. Participaron en la mesa redonda, en nombre de la Asociación Internacional de Hispanistas, Jean François Botrel y Aurora Egido.

Un año más tarde, en la Universidad de Silesia, tuvo lugar el primer Encuentros, es decir, el Primer Simposio Internacional de la Asociación Polaca de Hispanistas. Katowice, 30 de noviembre - 2 de diciembre de 2006, que continuaba con las iniciativas de promoción del hispanismo polaco, emprendidas anteriormente por la profesora Teresa Eminowicz en colaboración con los compañeros de otros centros de estudios hispánicos en Polonia. La profesora Eminowicz no pudo estar con nosotros en Katowice. Se había retirado de la actividades de la vida académica, lo cual supuso una pérdida irreparable para el desarrollo dinámico del hispanismo en Polonia. Muchos de nosotros se encontraron con la profesora Eminowicz por última vez hace diez años, en el Collegium Novum de la Universidad Jaguelónica, durante la solemne entrega que se le hizo del tomo de Z Hiszpania w sercu. Studia dedykowane profesor Teresie Eminowicz-Jaśkowskiej. Con España en el corazón. Homenaje a la profesora Teresa Eminowicz (Studia Iberystyczne 7, 2008).

Asocio inevitablemente a Mnemósine - personaje mitológico, diosa de la memoria - con la profesora Eminowicz. Mnemósine era una titánide, madre de nueve musas, cada una de las cuales recibió un talento y una misión diferente. Recuerdo perfectamente nuestro último encuentro con la Profesora Eminowicz en el Collegium Novum, su mirada serena y llena de sabiduría durante la despedida. 
Cuando apenas hace un mes, el 25 de septiembre de 2018, me encontraba en la Sala de las Musas del Museo de El Prado, junto con otros dos polacos como parte del grupo de hispanistas de cinco continentes a los que su Alteza la Infanta Doña Margarita de Borbón y su marido Don Carlos Zurita, Duques de Soria, ofrecían una solemne cena, pude sentir la presencia espiritual de mi mentora, con la que ya había participado en más de una ocasión en actividades que tenían como fin la promoción de los estudios de hispánicas en nuestra parte de Europa.

Por ello para terminar quisiera citar las palabras que al día siguiente, el 26 de septiembre de 2018, durante el acto de Homenaje al Hispanismo Internacional en el Palacio Real de El Pardo Felipe VI, Rey de España, dirigió a los hispanistas no hispanos, representados por un grupo de sesenta hispanistas de todo el mundo invitados a Madrid por la Fundación Duques de Soria.

Nos encontramos hoy aquí para rendir un sincero, profundo y sentido homenaje a un colectivo muy especial, a un gran grupo humano formado por miles de doctores y licenciados universitarios de todo el mundo que, sin ser -en su mayoría- hispanohablantes de nacimiento, dedican su vida profesional con verdadera pasión a promover nuestra lengua y nuestra cultura. Estos "hispanistas no hispanos", enamorados de nuestra cultura y volcados - personal y profesionalmente- en ella, difunden desde universidades e instituciones su conocimiento y entusiasmo por nuestro patrimonio cultural e histórico. Y lo hacen en beneficio de todos: en beneficio de las sociedades hispánicas que son así mejor conocidas en otros contextos internacionales; y de las sociedades no hispanas que se enriquecen con la aportación de nuestra cultura al mundo. La labor investigadora y docente de los hispanistas potencia, sin duda, el alcance universal de nuestra cultura al tiempo que contribuye a reforzar el prestigio de los países hispanohablantes. [...] Otra de las grandes virtudes del hispanismo internacional es su efecto multiplicador, porque la condición de docentes, en la mayoría de los casos, de sus representantes hace que su pasión se transmita, año tras año, a sucesivas audiencias y generaciones de estudiantes. Es además muy relevante el impacto de las aportaciones científicas de los hispanistas, 
así como la cifra de estudiantes que, cada curso en todo el mundo, reciben de sus profesores la semilla de la atracción hacia nuestras culturas. [...] Podemos decir que conocemos muy bien el gran valor de la aportación de los hispanistas internacionales. Por ello, nos corresponde expresarles nuestra admiración y nuestra gratitud ${ }^{2}$.

Estas palabras de profunda admiración y agradecimiento por la gran aportación al desarrollo de los estudios hispánicos fuera de España van dirigidas igualmente a la profesora Teresa Eminowicz-Jaśkowska.

Wrocław, 15 de octubre de 2018

2 "Palabras de S.M. el Rey en el Homenaje al Hispanismo Internacional", Palacio Real de El Pardo, Madrid, 26.09.2018. Discurso diponible en: [on-line] http://www.casareal.es/ES/Actividades/Paginas/actividades_discursos_detalle. aspx?data $=6053,[15.10 .2008]$ 